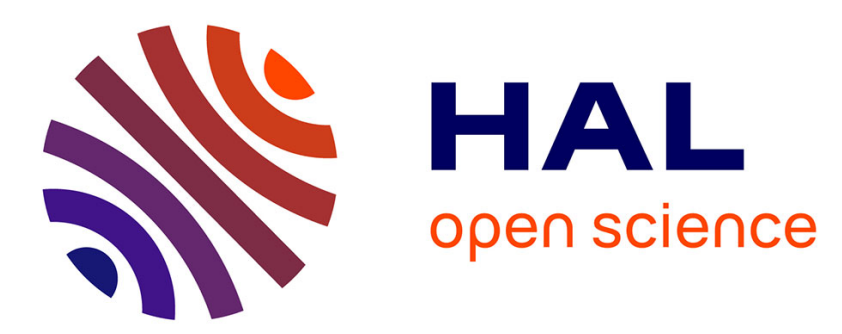

\title{
Lymph node ratio, number of excised nodes and sentinel-node concepts in breast cancer
}

Nadia Peparini, Piero Chirletti

\section{To cite this version:}

Nadia Peparini, Piero Chirletti. Lymph node ratio, number of excised nodes and sentinel-node concepts in breast cancer. Breast Cancer Research and Treatment, 2010, 126 (3), pp.829-833. 10.1007/s10549-010-1296-y . hal-00604407

\section{HAL Id: hal-00604407 https://hal.science/hal-00604407}

Submitted on 29 Jun 2011

HAL is a multi-disciplinary open access archive for the deposit and dissemination of scientific research documents, whether they are published or not. The documents may come from teaching and research institutions in France or abroad, or from public or private research centers.
L'archive ouverte pluridisciplinaire HAL, est destinée au dépôt et à la diffusion de documents scientifiques de niveau recherche, publiés ou non, émanant des établissements d'enseignement et de recherche français ou étrangers, des laboratoires publics ou privés. 
Authors: Nadia Peparini , MD, PhD, Piero Chirletti, MD, Professor

Title: Lymph node ratio, number of excised nodes and sentinel-node concepts in breast cancer.

Affiliation: Department of General Surgery "Francesco Durante"

La Sapienza University

Viale del Policlinico, 155

00161 Rome

Italy

Phone/fax +39649970385

Corresponding Author and requests for reprints : Nadia Peparini, MD, $\mathrm{PhD}$

via Quirina 26

02032 Passo Corese (RI)

Italy

Phone: + 363392203940

Fax : +39765488423

e-mail : nadiapeparini@yahoo.it 
To the Editor

We read with great interest the review by Pepels and colleagues on the safety of withholding axillary lymph node dissection (ALND) to patients with clinically node-negative breast cancer [1]. According to the survival and local control results from the NSABP B-32 randomised fase 3 trial [2] the Authors concluded that in patients with $\mathrm{T} 1$ or small $\mathrm{T} 2$ sentinel node (SN)-negative breast cancer omission of ALND can be regarded as safe. They pointed out that there is a shift toward omitting completion ALND in SN-positive patients but estimated that in $\mathrm{SN}$-positive series the overall axillary recurrence rates were 2,8 times higher than for the $\mathrm{SN}$ negative studies, and axillary recurrence rates after 5 and 8 years might be as high as $13 \%$ and $18 \%$ respectively. They highlighted that in many patients with a positive SN withholding ALND may be not safe and that the role of systemic therapy have to be elucidated to establish a potential role for avoiding ALND in selected SN-positive cases.

Most of published studies on SN associated with ALND reported not insignificant prevalence of falsenegative results, but the clinical consequences of these false-negative $\mathrm{SN}$ were fewer than expected. The discrepancy between prevalence of false-negative SN and lower prevalence of nodal recurrence in patients without definitive axillary treatment, the discrepancy between prevalence of axillary failure in clinically node-negative patients who do not undergo ALND and prevalence of positive nodes in clinically node-negative patients undergoing ALND have been partly attributed to the systemic therapies which are administered to the most SNnegative patients [3-5]. On the one hand in contemporary practice of breast cancer treatment on the one hand there is a shift toward using systemic therapies as a substitute for potentially incomplete surgery (i.e. SN biopsy alone in $\mathrm{SN}$-positive cases) more than as a complement to complete surgery. On the other hand, ratio of involved to total number of LNs (LNR) was found to be a better prognostic factor than the number of positive lymph nodes (LNs) for staging node-positive breast cancer in series of patients treated in era of systemic therapy [6-8]. An association between survival and extension of nodal dissection evaluated by the total number of the removed LNs, the number of removed uninvolved LNs, LNR with improvement in outcome in cases of more extended lymphadenectomy has been reported for melanoma and for colon, lung, gastric, pancreatic, esophageal and breast cancers. LNR can minimize the stage migration produced by extended nodal dissection; using LNR rather than the absolute number of positive nodes reduces inter-institutional differences in outcome that may exist because of variations in the number of nodes excised. However the best cut-off points of LN ratio required for a staging classification of each malignant tumor is controversial. Better prognosis has been reported with higher number of dissected normal nodes in histologically node-positive and node-negative gastrointestinal tumors and several studies on breast cancer showed survival advantages after removal of many axillary nodes even if all regional nodes were pathologically negative [4,9]. Although the Will Rogers effect (i.e., stage migration) was the most 
evident confounding factor, the prognostic improvement was attributed mostly to removal of nodes with micrometastases that were undetectable by routine histologic examination but which had prognostic impact. The concept of better prognosis by increase of the total number of dissected nodes and mostly by lowering of LNR (which minimizes the "stage migration" effect) supports the thesis of the therapeutic value of extended nodal dissection. However whether or not ALND confers a survival advantage in breast cancer with micrometastatic or macrometastatic SNs in era of systemic therapy is questioned. Wasif and coll. showed that current ASCO guidelines recommending routine ALND following identification of micrometastasis in sentinel nodes (SNs) are being followed in only $60 \%$ of cases and that the use of SN biopsy alone for axillary staging in cases of micrometastatic SNs may underestimate a $20 \%$ of patients with additional involved nonsentinel nodes revealed by ALND [10]. The prognostic value of micrometastasis and isolated tumor cells (ITCs) in SNs in terms of associated additional positive nodes and distant recurrences is controversial. In the preliminary report from the EORTC 10981-22023 AMAROS Trial the further nodal involvement in patients with macrometastasis, micrometastasis and ITCs in SNs was 41\%, $18 \%$ and $18 \%$ respectively[11], according to the results of other studies underlined in the review by Pepels and colleagues. Maaskant-Braat and colleagues in their report on this Journal found no statistically significant difference in survival between patients with micrometastasis or ITCs in SNs compared to those patients with tumor-free SNs [12]. However in the study by de Boer and coll. ITCs and micrometastasis in regional LNs resulted be associated with a reduced 5-year rate of disease-free survival among women with earlystage breast cancer who did not receive adjuvant therapy, without significant differences in outcome between ITCs and micrometastasis [13]. Truong and coll. showed that similar to patients with macroscopic positive nodes, mortality hazards in patients with micrometastatic nodal disease increased with increased number of positive nodes and LNR [8].

Although the prognostic impact of micrometastasis and ITCs is under debate, it is known that the occurrence of locoregional failures confers poor prognosis[14].

At present SN biopsy can be considered to be an effective procedure in the assessment of regional nodal status in clinically N0 cancer patients, and LNR considered to be the most effective prognostic factor that assesses the extent of therapeutic nodal dissection in node-positive tumors [15].In breast cancer the concept of LNR cannot be consistent with the concept of SN biopsy if completion ALND is considered unnecessary in SN-positive patients, and if staging by SN biopsy is considered to be the only necessary surgical treatment for these patients. Moreover performing SN biopsy alone in $\mathrm{pN} 1_{\mathrm{mi}} \mathrm{SN}$ patients cannot be consistent with the prognostic value of LNR in $\mathrm{pN}_{\mathrm{mi}}$ : if the therapeutic or prognostic value of LNR in microscopically SN-positive tumors is accepted, completion ALND will have to be done in all SN-positive tumors (apart from micrometastatic or macrometastatic SNs). In fact the risk of additional non-SN involvement associated to micrometastatic SN involvement is not 
negligible: SN biopsy improves pathological nodal assessment detecting otherwise misdiagnosed nodal micrometastases by adopting multistep sectioning, immunohistochemistry or RT-PCR but it should be considered that if these same techniques are applied to non-sentinel nodes, the false-negative rate of SNs will increase.

In conclusion avoiding completion ALND in patients with micrometastatic or macrometastatic SNs is not consistent with the concept of LNR as a prognostic factor in these patients. The potential role of systemic therapy for avoiding ALND in selected SN-positive patients need further to be elucidated but it should be considered that the prognostic value of LNR in identifying higher-risk node-positive cases warranting more aggressive systemic therapy may be estimated only by ALND.

\section{References}

1. Pepals MJ, Vestjens JHMJ, de Boer M et al (2010) Safety of avoiding routine use of axillary dissection in early stage breast cancer: a systematic review.Breast Cancer Res Treat doi:10.1007/s10549-010-1210-7

2. Krag DN, Anderson SJ, Julian TB et al (2010) Sentinel-lymph-node resection compared woth conventional axillary-lymph node dissection in clinically node-negative patients with breast cancer: overall survival findings from the NSABP B-32 randomised phase 3 trial. Lancet Oncol 2010;11:927-933

3. Veronesi U, Viale G, Paganelli G et al (2010) Sentinel node biopsy in breast cancer. Ten year results of a randomized controlled study. Ann Surg 251:595-600

4. Moon HG, Han W, Noh DY (2010) Comparable survival between pN0 breast cancer patients undergoing sentinel node biopsy and extensive axillary dissection: a report from the Korean Breast Cancer Society. J Clin Oncol 28:1692-1699

5. Sanghani M, Balk EM, Cady B (2009) Impact of axillary lymph node dissection on breast cancer outcome in clinically node negative patients. Cancer 115:1613-205.

6. Vinh-Hung V, Verkooijen HM, Fioretta G et al (2009) Lymph node ratio as an alternative to pN staging in node-positive breast cancer. J Clin Oncol 27:1062-1068.

7. Danko ME, Bennett KM, Zhai J et al (2010) Improved staging in node-positive breast cancer patients using lymph node ratio: results in 1788 patients with long-term follow-up. J Am Coll Surg 2010;210:797-807

8. Troung PT, Lesperance M, Li KH et al (2010) Micrometastatic node-positive breast cancer: long-termoutcomes and identification of high-risk subsets in a large population-based series.

Ann Surg Oncol 17:2138-2146

9. Axelsson CK, Durino M, Christansen PM et al (2009) Impact on regional recurrence and survival of axillary surgery in women with node-negative primary breast cancer. Br J Surg 96:40-46

10. Wasif N, Maggard MA, Ko CY et al (2010) Underuse of axillary dissection for management of sentinel node 
micrometastases in breast cancer. Arch Surg 145:161-166

11. Straver ME, Meijnen P, van Tienhoven G et al (2010) Sentinel node identification rate and nodal involvement in the EORTC 10981-22023 AMAROS Trial. Ann Surg Oncol 17:1854-1861

12.Maaskant-Braat AJ, van de Poll-Franse LV, Voogd AC et al (2010) Sentinel node micrometastases in breast cancer do not affect prognosis: a population-based study. Breast Cancer Res Treat doi:10.1007s10549-010-1086-6 13.de Boer M, van Deurzen C, van Dijck JAAM et al (2009) Micrometastases or isolated tumor cells and the outcome of breast cancer. N Engl J Med 361;653-663

14. Anderson SJ, Wapnir I, Dignam JJ et al (2009) Prognosis after ipsilateral breast tumor recurrence and locoregional recurrences in patients treated by breast-conserving therapy in five national surgical adjuvant breast and bowel project protocols of node-negative breast cancer. J Clin Oncol 27:2466-2473

15. Xing Y, Badgwell BD, Ross MI et al (2009) Lymph node ratio predicts disease-specific survival in melanoma patients. Cancer 115:2505-2513

To the editor

We like to thank dr. Peparini for her interesting letter-to-the-editor regarding our systematic review on the safety of avoiding routine use of axillary lymph node dissection (ALND) in early breast cancer patients [1,2]. She agrees on our conclusion that omitting ALND in sentinel node (SN) negative patients can be considered a safe strategy. Further, she also fully agrees with our second message, that is that in SN positive patients still many issues need to be solved before omission of ALND can be recommended to all these patients.

Dr. Peparini argues that there are two additional reasons why ALND cannot be omitted in SN positive patients, besides low number of patients followed up and absence of well-defined selection criteria to be used. The first additional argument concerns the lack of information on the lymph node ratio (LNR) if no completion ALND is performed. The second argument concerns possible changes in systemic treatment choices depending on ALND, and more specifically treatment choices related to the presence of isolated tumor cells and micrometastases. Although we share the same vision on the preferred strategy in SN positive patients, we are not convinced that the aforementioned arguments really further support our conclusion.

The LNR is the ratio of positive to excised number of nodes. Many studies have reported that in breast cancer the LNR is a stronger prognosticator than the absolute number of positive nodes [3-6]. With more negative nodes being removed, the LNR reduces and prognosis improves. In addition, several studies have shown that also in node-negative patients clinical outcome is 
associated with number of (negative) nodes excised [7,8]. The argument in favour of an extensive ALND is that if more nodes are excised also microscopic disease is resected, preventing outgrowth and dissemination of disease. As such, ALND might offer therapeutic benefit. On the other hand, there may be stage migration when more nodes are removed, for example in patients with two resected SNs that are both positive, that could actually have a larger number of positive nodes if only more nodes would have been investigated. So, the meaning of 'two positive' nodes is different for patients with more versus those with less nodes excised. This latter concept relates the improved outcome of extensive ALND to the more accurate staging process and not necessarily to a therapeutic effect of ALND. This latter hypothesis may, however, not be relevant for patients who have undergone an SN procedure. The SN is by definition already a more accurate staging procedure than conventional ALND, and therefore, the number of negative nodes removed may be less relevant. A recent study that compared survival between pN0 breast cancer patients who had undergone more or less extensive ALND and pN0 patients who had an SN procedure confirmed this. Although extensive ALND was associated with better survival than limited ALND, SN only patients also had an excellent survival [7].

The second issue concerns the question of non-SN involvement, including macrometastatic disease, in case of $\mathrm{SN}$ micrometastases and if such additional information would change adjuvant systemic therapy choices. The chance of further lymph node metastases beyond the $\mathrm{SN}$ is $12.3 \%$ in case of SN isolated tumour cells (64\% macrometastases) and $20 \%$ in case of micrometastases [9]. Previously, we have shown in the Dutch MIRROR study that isolated tumor cells and micrometastases as final nodal status are significantly associated with increased risk of disease-events at a hazard ratio of about 1.5 as compared with patients having node-negative disease [10]. Some other SN studies could [11,12] but some could not confirm this association between micrometastatic disease and clinical outcome [13-15]. However, it is noted that the MIRROR study is by far the largest SN study on prognostic relevance of isolated tumor cells and micrometatases, with outcome being assessed in patients who had not received systemic therapy and SN classification on full central pathology revision, and by such offering the most robust data on this issue. Moreover, a comparable hazard ratio of around 1.45 was seen in a meta-analysis on studies from the pre-SN era [16]. Therefore, we recommend to consider the use of adjuvant systemic therapy in these patients, and think that systemic treatment choices should not depend on the number of positive nodes that have been detected.

To conclude, we agree with Peparini that for most patients it is yet too soon to routinely implement omission of ALND in SN positive patients. Although many questions still need to be addressed, we are not convinced that LNR is an important factor when the SN procedure is being used.

\section{References}

1. Peparini N (2010) Lymph node ratio, number of excised nodes and sentinel-node concepts in breast cancer. Breast Cancer Res Treat

2. Pepels MJ, Vestjens JHMJ, de Boer M et al (2010) Safety of avoiding routine use of axillary dissection in early stage breast cancer: a systematic review. Breast Cancer Res Treat doi:10.1007/s10549-010-1210-7

3. Woodward WA, Vinh-Hung V, Ueno NT et al (2006) Prognostic value of nodal ratios in node-positive breast cancer. J Clin Oncol 24:2910-2916

4. Truong PT, Lesperance M, Li KH et al (2010) Micrometastatic node-positive breast cancer: long-term outcomes and identification of high-risk subsets in a large population-based series. Ann Surg Oncol 17:21382146

5. Danko ME, Bennett KM, Zhai J et al (2010) Improved staging in node-positive breast cancer patients using lymph node ratio: results in 1788 patients with long-term follow-up. J Am Coll Surg 2010;210:797-807 
6. Vinh-Hung V, Verkooijen HM, Fioretta $\mathrm{G}$ et al (2009) Lymph node ratio as an alternative to pN staging in node-positive breast cancer. J Clin Oncol 27:1062-1068.

7. Moon HG, Han W, Noh DY (2010) Comparable survival between pNO breast cancer patients undergoing sentinel node biopsy and extensive axillary dissection: a report from the Korean Breast Cancer Society. J Clin Oncol 28:1692-1699

8. Axelsson CK, Durino M, Christansen PM et al (2009) Impact on regional recurrence and survival of axillary surgery in women with node-negative primary breast cancer. Br J Surg 96:40-46

9. Van Deurzen CH, de Boer M, Monninkhof EM et al (2008) Non-sentinel lymph node metastases associated with isolated breast cancer cells in the sentinel node. J Natl Cancer Inst 100:1574-1580

10. de Boer M, van Deurzen C, van Dijck JAAM et al (2009) Micrometastases or isolated tumor cells and the outcome of breast cancer. N Engl J Med 361;653-663

11. Pugliese M, Stempel M, Patil S et al (2010) The clinical impact and outcomes of immunohistochemistry-only metastasis in breast cancer. Am J Surg 200:368-73

12. Leidenius MH, Vironen JH, Heikkilä PS et al (2010) Influence of isolated tumor cells in sentinel nodes on outcome in small, node-negative (pT1N0M0) breast cancer. Ann Surg Oncol 17:254-62

13. Hansen NM, Grube B, Ye X et al (2009) Impact of micrometastases in the sentinel node of patients with invasive breast cancer. J Clin Oncol 27:4679-84

14. Maaskant-Braat AJ, van de Poll-Franse LV, Voogd AC et al (2010) Sentinel node micrometastases in breast cancer do not affect prognosis: a population-based study. Breast Cancer Res Treat. doi:10.1007s10549-0101086-6

15. Andersson Y, Frisell J, Sylvan M et al (2010) Breast cancer survival in relation to the metastatic tumor burden in axillary lymph nodes. J Clin Oncol 28:2868-73

16. de Boer M, van Dijck JAAM, Bult P et al (2010) Breast cancer prognosis and occult lymph node metastases, isolated tumor cells, and micrometastases. J Natl Cancer Inst 102:410-425

Manon J. Pepels ${ }^{1}$, Johanna H.M.J.Vestjens ${ }^{1}$, Maaike de Boer ${ }^{1,5}$, Marjolein Smidt ${ }^{2}$, Paul J. van Diest ${ }^{3}$, George F. Borm ${ }^{4}$, Vivianne C.G. Tjan-Heijnen ${ }^{1}$

${ }^{1}$ Division of Medical Oncology, Department of Internal Medicine, and ${ }^{2}$ Department of Surgery, GROW - School for Oncology and Developmental Biology, Maastricht University Medical Centre, Maastricht; ${ }^{3}$ University Medical Centre Utrecht, Utrecht; ${ }^{4}$ Department of Epidemiology, Biostatistics and HTA, Radboud University Nijmegen Medical Centre, Nijmegen; ${ }^{5}$ Department of Medical Oncology, Radboud University Nijmegen Medical Centre, Nijmegen

Address for correspondence:

Vivianne C.G. Tjan-Heijnen, M.D., Ph.D.

Division of Medical Oncology, Department of Internal Medicine

Maastricht University Medical Centre

P.O. Box 5800

6202 AZ Maastricht, the Netherlands 
phone +3143 3877025; fax +31433876281

email: vcg.tjan.heijnen@mumc.nl 